\title{
ANÁLISE EXPLORATÓRIA DE INDICADORES DE DESEMPENHO
}

\section{Exploratory analysis of performance indicators}

\begin{abstract}
Alini da Silva
E-mail: alinicont@gmail.com

Mestre em Ciências Contábeis pela Fundação Universidade Regional de Blumenau; Doutoranda em Ciências Contábeis e Administração pela Fundação Universidade Regional de Blumenau; Bolsista Capes na Fundação Universidade Regional de Blumenau. Endereço para contato: Rua Antônio da Veiga, 140, Victor Konder, 89030-90, Blumenau, Santa Catarina, Brasil. https://orcid.org/0000-0002-7043-5566

Sheila Patrícia Ramos E-mail: spr80sc@gmail.com Mestre em Administração pela Fundação Universidade Regional de Blumenau; Doutoranda em Ciências Contábeis e Administração pela Fundação Universidade Regional de Blumenau; Bolsista Capes na Fundação Universidade Regional de Blumenau. https://orcid.org/0000-0002-9903-5291

Adriana Kroenke

E-mail: akroenke@furb.br Doutora em Métodos Numéricos em Engenharia pela Universidade Federal do Paraná; Mestre em Ciências Contábeis pela Fundação Universidade Regional de Blumenau; Professora no Programa de Pós-graduação em Ciências Contábeis da Fundação Universidade Regional de Blumenau. https://orcid.org/0000-0001-6625-3017
\end{abstract}

Nelson Hein E-mail: hein@furb.br Doutor em Engenharia de Produção pela Universidade Federal de Santa Catarina; Mestre em Engenharia de Produção pela Universidade Federal de Santa Catarina; Professor no Programa de Pós-graduação em Ciências Contábeis da Fundação Universidade Regional de Blumenau. https://orcid.org/0000-0002-8350-9480 
A presente pesquisa teve por objetivo verificar o agrupamento de indicadores de desempenho em três dimensões, como: desempenho econômico, desempenho financeiro e desempenho de mercado, por meio da análise fatorial exploratória. Para tanto, utilizou-se metodologia com caráter descritivo, documental e quantitativo. A amostra do estudo correspondeu a 101 empresas listadas na Brasil, Bolsa e Balcão - B3, no período de 2010 a 2016. Para a análise dos dados, utilizou-se análise fatorial exploratória. Os resultados demonstraram que os indicadores de desempenho financeiro (liquidez corrente, liquidez seca, liquidez imediata e liquidez geral) se agruparam em um único fator de acordo com o estipulado pela literatura, os demais grupos de desempenho econômico e de mercado não tiveram a associação de todos os indicadores conforme estipulado pela literatura. Observou-se, também, que conforme há variação dos setores de atuação, há variação na importância de indicadores econômicos, financeiros e de mercado.

Palavras-chave: Desempenho econômico. Desempenho financeiro. Desempenho de mercado. Setores de atuação.

\section{Abstract}

The present study aimed to verify the grouping of performance indicators in three dimensions, such as: economic performance, financial performance and market performance, through exploratory factor analysis. For that, a descriptive, documental and quantitative methodology was used. The study sample corresponded to 101 companies listed on the Brazil, Bolsa e Balcão - B3, from 2010 to 2016. Data analysis was performed using an exploratory factorial analysis. The results showed that the financial performance indicators (current liquidity, dry liquidity, immediate liquidity and general liquidity) were grouped in a single factor according to the literature, the other groups of economic and market performance, did not have the association of indicators as stipulated in the literature. It was also observed that, as there is variation in the sectors of activity, there is variation in the importance of economic, financial and market indicators.

Keywords: Economic performance. Financial performance. Market performance. Actuation sectors.

\section{INTRODUÇÃO}

O desempenho das empresas pode ser medido por diversas formas; ao incorporar aspectos financeiros, pode ser mensurado por índices de lucratividade, crescimento das vendas, valor de mercado, entre outras medidas (Brito, Brito, \& Morganti, 2009; Venkatraman \& Ramanujam, 1986).

A mensuração de desempenho das empresas, de acordo com Hendriksen e Van Breda (1999), pode ser observada por informações monetárias bem como por informações não monetárias. De acordo com Teixeira e Amaro (2013), apesar de cada vez mais as organizações avaliarem seu desempenho por informações não financeiras, a medição do desempenho por meio de indicadores econômicos, financeiros e de mercado é muito importante para a empresa, pois apresenta o reflexo das decisões do gestor e da empresa na criação de valor desta no mercado. Esse aspecto já vinha sendo retrato no início dos anos 2000 por Dumontier 
e Raffournier (2002), os quais afirmaram que a decisão dos gestores e o desempenho destes podiam ser avaliados também por meio da mensuração do desempenho da empresa.

Em razão do acirrado ambiente competitivo em que as empresas estão inseridas, estas precisam demonstrar um elevado desempenho organizacional e principalmente monetário, a fim de alcançarem as metas e objetivos traçados (Fischmann \& Zilber, 2009). A principal finalidade de se avaliar o desempenho das empresas é observar a eficiência das políticas, estratégias e diretrizes adotadas por estas, também com base em informações passadas e correntes se pode prever o desempenho futuro da empresa, indicando possibilidades de alteração ou incremento de estratégias a fim de se alcançar o objetivo organizacional (Healy \& Palepu, 2007).

Somada a isso, segundo Macedo e Corrar (2010), a análise de relatórios financeiros e contábeis é utilizada por todas as empresas, sendo que algumas utilizam mais e outras menos, em que essa variação é decorrente do tipo de organização e setor de atuação, principalmente. As organizações utilizam esses mecanismos de avaliação de desempenho para aumentar a possibilidade de lucratividade com relação à concorrência.

De acordo com Young e O’Byrn (2003), há diferentes métricas e indicadores monetários para avaliar o desempenho das empresas e auxiliar os gestores a atingirem os escopos organizacionais. Segundo Bortoluzzi, Ensslin, Lyrio, \& Ensslin (2011), os índices contábeis tradicionais para avaliar o desempenho da empresa são os de liquidez, rentabilidade e estrutura de capital. Ainda, tem-se os indicadores de mercado, como: preço da ação, $Q$ de Tobin (QT) e EVA. Há inúmeros índices absolutos e relativos que auxiliam a medição do desempenho monetário das empresas.

Diante desse cenário, retrata-se o desempenho monetário em alguns agrupamentos, como os indicadores de desempenho econômico, financeiro e de mercado (Silveira, 2002; Bacidore, Boquist, Milbourn, \& Thakor, 1997; Rappaport, 1998). Dessa forma, diante desse contexto, surge a problemática de se investigar como os indicadores monetários se agrupam e se estes vão ao encontro do estipulado pela literatura.

Por tal motivo, estipulou-se a seguinte questão de pesquisa: quais são os indicadores de desempenho que se agrupam em três dimensões, como desempenho econômico, desempenho financeiro e desempenho de mercado, por meio da análise fatorial exploratória? A fim de auxiliar na resolução do problema, delimitou-se como objetivo geral verificar o agrupamento de indicadores de desempenho em três dimensões: desempenho econômico, desempenho financeiro e desempenho de mercado, por meio da análise fatorial exploratória. Ainda, como objetivo específico, tem-se por intuito analisar os determinantes de desempenho das empresas de acordo com cada setor, visto que na visão de Macedo e Corrar (2010), a utilização dos indicadores de desempenho varia de acordo com o setor de atuação da empresa.

Este estudo justifica-se por apresentar evidências empíricas de empresas brasileiras ao longo de 10 anos, demonstrando o agrupamento de indicadores de desempenho conforme 
- estipulado pela literatura, com a especificação de indicadores financeiros, econômicos e de mercado. Além disso, foram identificados os principais indicadores de desempenho das empresas de acordo com cada setor, evidenciando os determinantes para as empresas e que merecem maior atenção e gerenciamento por parte destas.

\section{DESEMPENHO DE EMPRESAS}

Apresentam-se nesta seção as principais referências acerca do desempenho econômico, do desempenho financeiro e do desempenho de mercado, os quais se fazem necessário para a construção das hipóteses do estudo.

\subsection{DESEMPENHO ECONÔMICO}

De acordo com Pimentel, Braga, e Nova (2005) a rentabilidade pode ser definida como o grau de êxito econômico obtido pela empresa com relação ao capital investido. Esse êxito econômico é determinado pela magnitude do lucro líquido contábil.

Os índices de rentabilidade, segundo Gitman (2010), permitem avaliar os lucros da empresa em relação a um dado nível de vendas, ativos ou investimentos feitos pelos proprietários. Ainda, de acordo com Gitman (2010), se não houver lucro uma empresa não atrai capital externo.

Pimentel et al. (2005) afirmam que a avaliação da rentabilidade costuma ser feita por meio do ROA (Lucro líquido/Ativo total) e do ROE (Lucro líquido/Patrimônio líquido), sendo essas medidas finais do grau de êxito econômico.

Gitman (2010) considera para medir o desempenho econômico a margem de lucro bruto (receita de vendas - custo das mercadorias vendidas/receita de vendas), a margem de lucro operacional (lucro operacional/receita de vendas), a margem de lucro líquido (lucro disponível para os acionistas ordinários/receitas de vendas), o lucro por ação (lucro disponível para os acionistas ordinários/número de ações ordinárias em circulação), o retorno sobre o ativo total (ROA - lucro disponível para os acionistas ordinários/ativo total) e o retorno sobre o capital próprio (ROE - lucro disponível para os acionistas ordinários/patrimônio líquido dos acionistas ordinários).

Groppelli e Nikbakht (2002) consideram como medida de desempenho econômico o retorno sobre o patrimônio Líquido - ROI ((lucro líquido/vendas) versus (vendas/ativo total $)=($ lucro líquido/ativo total) desenvolvido pela Companhia Du Pont para medir os efeitos combinados da margem de lucro líquido e do giro do ativo total. O objetivo é comparar a forma pela qual a empresa gera lucros e a forma como usa seus ativos para gerar vendas. 
Shin e Soenen (2000 citado em Pimentel, 2008) utilizaram como medida de rentabilidade a relação entre o lucro operacional antes da depreciação (EBITDA) e o total de ativos (ROI). Pimentel (2008), Smyth, Samuels, e Tzoannos (1972) utilizaram lucro líquido dividido pelo total de ativo ( $R O A$ ) como medida de desempenho econômico. Braga, Nossa, e Marques (2004), além de utilizarem o retorno sobre o ativo (ROA - lucro líquido/total de ativos), utilizaram-no sobre o patrimônio líquido decomposto (ROE decomposto - ROA versus ativo total/patrimônio líquido) como métricas de rentabilidade.

Uremadu, Egebidi, e Enyi (2012 citado em Luz, 2013) afirmam que o ROA mede a eficiência global da empresa em gerar lucros com ativos disponíveis, sendo equivalente ao ROI, porém é uma medida mais apropriada da eficiência operacional de uma empresa.

Em relação aos indicadores de rentabilidade, Gitman (2010) afirma que quanto maiores os seus valores, melhor o resultado gerado, já que medem a eficiência da empresa, além do retorno para os proprietários da organização e seus stakeholders.

Assim, de acordo com Groppelli e Nikbakht (2002), Gitman (2010) e Blatt (2001), os indicadores considerados mais utilizados para medir o desempenho econômico das empresas são ROE, ROA, margem de lucro bruto, margem de lucro operacional e margem de lucro líquido. Para tanto, buscando avaliar se esse agrupamento de índices contribui para medir o desempenho econômico das empresas, testa-se a seguinte hipótese de pesquisa:

H1: Os indicadores de desempenho ROA, ROE, margem de lucro bruto, margem de lucro operacional e margem de lucro líquido correspondem ao agrupamento de desempenho econômico das empresas brasileiras analisadas.

Matarazzo (2010) ressalta que o importante não é o cálculo da quantidade de índices, mas de um conjunto de índices que possibilite conhecer e entender a situação real da empresa, de acordo com o grau de profundidade esperada para a análise. $\mathrm{Na}$ avaliação do desempenho empresarial, por meio dos índices, analisa-se a situação financeira separadamente da situação econômica, na sequência juntam-se as conclusões dessas duas análises (Matarazzo, 2010). Firer e Williams (2003) argumentam que não há uma perspectiva teórica ou evidências empíricas suficientes que apoiem o uso de uma determinada medida de desempenho em detrimento das demais. Além, do desempenho econômico, tem-se como outro importante agrupamento o desempenho financeiro.

\subsection{DESEMPENHO FINANCEIRO}

Luz (2013) afirma que os indicadores de liquidez são índices capazes de predizer, no curto prazo, a situação de solvência ou de dificuldades financeiras da empresa e servem como fonte de informação aos stakeholders, sendo estes os principais indicadores de desempenho financeiro. 
Gitman (2010) afirma que os índices de liquidez medem a capacidade da empresa de saldar suas obrigações de curto prazo à medida que se tornam devidas. Tratam da solvência da posição financeira geral da empresa, ou seja, representam a facilidade de pagar as contas. Os índices de liquidez fornecem sinais antecipados de problemas de fluxo de caixa e insolvência quando a empresa apresenta liquidez baixa ou em declínio.

Conforme Pimentel et al. (2005), a liquidez constitui a capacidade de uma empresa em liquidar seus compromissos financeiros, nos prazos contratados. Os autores destacam que a manutenção é condição sine qua non para a continuidade dos negócios.

Groppelli e Nikbakht (2002) e Gitman (2010) destacam que as duas medidas fundamentais de liquidez são a liquidez corrente (ativo circulante/passivo circulante) e a liquidez seca (ativo circulante-estoques/passivo circulante). $O$ índice de liquidez corrente mede a capacidade de a empresa pagar suas obrigações de curto prazo. E o índice de liquidez seca assemelha-se à liquidez corrente, entretanto, exclui-se do cálculo o estoque.

Luz (2013) acrescenta também o índice de liquidez imediata (disponível/passivo circulante) que busca identificar o quanto de disponibilidade a empresa possui de imediato para quitar suas obrigações. Já Blatt (2001) apresenta também o índice de liquidez geral ((ativo circulante + realizável em longo prazo)/(passivo circulante + exigível em longo prazo)) que mostra a solidez financeira de uma empresa em longo prazo.

De acordo com Gitman (2010), os índices de liquidez são válidos quando comparados ao longo do tempo e com outras empresas do mesmo setor. Conforme Van Horne (1995), quanto menor a liquidez, maior o risco de cumprimento das obrigações correntes. A liquidez está vinculada à capacidade de geração de lucros e influencia a rentabilidade e os riscos da empresa (Van Horne, 1995).

Assim, conforme Groppelli e Nikbakht (2002), Gitman (2010), Blatt (2001) e Luz (2013), os indicadores considerados tradicionais utilizados para medir o desempenho financeiro das empresas são liquidez corrente, liquidez seca, liquidez imediata e liquidez geral. Para tanto, buscando avaliar se esse agrupamento de índices contribui, em sua totalidade, para medir o desempenho financeiro das empresas, apresenta-se a seguinte hipótese de pesquisa:

H2: Os indicadores de desempenho liquidez corrente, liquidez seca, liquidez imediata e liquidez geral correspondem ao agrupamento de desempenho financeiro das empresas brasileiras analisadas.

Além do desempenho financeiro e econômico, conforme seção anterior, tem-se o agrupamento de indicadores que podem compor o desempenho de mercado. 


\subsection{DESEMPENHO DE MERCADO}

A avaliação do desempenho de mercado, na opinião de Wernke e Lembeck (2004), facilita a empresa na tomada de decisão com o intuito de ter maior competitividade no mercado. Ainda, segundo os autores, ao optar por utilizar esse tipo de indicador de desempenho, a empresa pode reduzir a lucratividade, ou seja, os índices de rentabilidade, entretanto, estará primando pela diferenciação perante os concorrentes e aumentará sua competitividade.

Sob o ponto de vista das finanças, o grande objetivo financeiro dos gestores das empresas é proporcionar incremento de valor da empresa para os acionistas, demonstrando o quanto de valor foi criado com o valor investido por estes. Para o acionista, o que mais interessa é que seu investimento gere retorno o suficiente para cobrir riscos de crédito e repor o dinheiro investido. Essa valorização da empresa no mercado ocorre quando as decisões implementadas por esta são valorizadas pelo mercado, o que aumenta a atratividade das ações e consequentemente cria valor (Frezatti, 1998).

Para Souza e Martins (2010) a avaliação do desempenho da empresa demonstra a forma como a empresa visualiza o mercado, demonstrando quais são as políticas que ela deve definir para alcançar a eficiência. A mensuração do desempenho de mercado é, muitas vezes, associada ao valor que a empresa possui para o mercado, o que, para Silveira (2002), pode ser observado pelo índice $Q$ de Tobin, para Bacidore et al. (1997) é observado pelo EVA e para Rappaport (1998) também pode ser avaliado por meio do lucro por ação e retorno das ações da empresa.

De acordo com Silveira (2002), há diferentes definições para desempenho de mercado elou valor da empresa no mercado, todavia, para ele, a representação é feita principalmente pelo indicador de $\mathrm{Q}$ de Tobin ( $\mathrm{QT}$ ). $\mathrm{O} \mathrm{Q}$ de Tobin ( $\mathrm{OT}$ ) é um indicador utilizado para avaliar o valor da empresa, o qual é definido pela soma entre o valor de mercado das ações ordinárias, das ações preferenciais e o valor contábil da diminuição do ativo circulante com as dívidas de curto e longo prazos, isso tudo dividido pelo ativo total da companhia.

A medida de desempenho EVA reporta uma análise profunda do mercado, esse indicador verifica a situação da empresa com indicadores contábeis publicados e informações complementares (Bacidore et al., 1997). O EVA foi originalmente desenvolvido por Stern Stewart na década de 1980, baseado no indicador de lucro econômico ou lucro residual desenvolvido por Alfred Marshall. Esse indicador possui como conceito o lucro gerado e que excede a remuneração do capital empregado pelo custo de oportunidade (Santos, 2006).

Ainda, como indicadores de desempenho de mercado, tem-se o lucro por ação e o retorno da ação, os quais retratam o aumento de valor da empresa nesse cenário (Rappaport, 1998). O lucro por ação demonstra o lucro gerado em relação à quantidade de ações da 
empresa, enquanto que o retorno da ação representa a compra e a venda de ações da empresa, o que reflete em retornos positivos e/ou negativos.

Dessa forma, com base nos autores Silveira (2002), Bacidore et al. (1997) e Rappaport (1998), pode-se inferir que o agrupamento de acordo com a literatura para os indicadores de mercado e que representam a criação de valor das empresas no mercado, correspondem ao $\mathrm{Q}$ de Tobin, lucro por ação e retorno da ação. A variável EVA, em razão da sua difícil medição, não foi compreendida no atual estudo. Por tal motivo, a fim de avaliar se esse agrupamento se comprova nas empresas e no período analisado, delimitou-se a terceira hipótese do estudo:

H3: Os indicadores de desempenho $Q$ de Tobin (QT), lucro por ação e retorno da ação correspondem ao agrupamento de desempenho de mercado das empresas brasileiras analisadas.

Observa-se na literatura diversas variáveis que podem medir o desempenho da empresa, sendo estas diferenciadas por suas características, como rentabilidade, liquidez ou de mercado, que de maneira geral, podem perfazer agrupamentos, como desempenho econômico, financeiro e de mercado, respectivamente. Assim, faz-se necessário explorar com evidências empíricas se essas variáveis se agrupam conforme o mencionado pela literatura.

\section{PROCEDIMENTOS METODOLÓGICOS}

A presente pesquisa, com o objetivo de verificar o agrupamento de indicadores de desempenho em três dimensões, como desempenho econômico, desempenho financeiro e desempenho de mercado, por meio de análise fatorial exploratória, configura-se como descritiva. O estudo descritivo, de acordo com Oliveira (2002), refere-se à identificação dos fenômenos e à explicação das relações de causa e efeito, que favorecem a compreensão de determinados fenômenos.

No que diz respeito aos procedimentos de estudo, enquadra-se como documental, pela utilização de dados oriundos de demonstrações financeiras para a análise de desempenho. A pesquisa documental, segundo Martins e Theóphilo (2007), refere-se à fonte de dados e informações auxiliares de documentos diversos. Quanto à abordagem do problema, configura-se como quantitativa, com a utilização de técnicas estatísticas para a análise de dados numéricos. Para Richardson (1989), o método quantitativo refere-se ao emprego da quantificação tanto na coleta de dados quanto na análise destes para demonstrar de forma estatística a relação entre os fenômenos. 


\subsection{POPULAÇÃO E AMOSTRA}

A população do estudo compreendeu todas as empresas listadas na Brasil, Bolsa e Balcão - B3, já a amostra compreendeu 101 empresas que possuíam todas as informações para a análise dos dados, no período de 2010 a 2015. A amostra foi segmentada, para uma análise acessória, nos 10 setores de atuação de acordo com a bolsa de valores, como: bens industriais; construção e transporte; consumo cíclico; consumo não cíclico; financeiro e outros; materiais básicos; petróleo, gás e biocombustíveis; tecnologia da informação; telecomunicações e utilidade pública.

\subsection{COLETA E ANÁLISE DOS DADOS}

A coleta dos dados para o cálculo dos indicadores econômicos, financeiro e de mercado ocorreu por meio da base de dados Economática. Na Tabela 1 pode-se observar as variáveis (índices) utilizadas no estudo, fórmulas, bem como os autores que as utilizaram em estudos relacionados.

Tabela 1

Constructo da pesquisa

\begin{tabular}{lcc}
\hline \multicolumn{1}{c}{ Variável } & Fórmula & \multicolumn{1}{c}{ Autores } \\
\hline Indicadores de desempenho econômico & & \\
\hline $\begin{array}{l}\text { Retorno sobre o patrimônio } \\
\text { líquido (ROE) }\end{array}$ & $\frac{\text { Lucro Líquido }}{\text { Patrimônio Líquido }}$ & $\begin{array}{l}\text { Blatt (2001), Groppelli e Nik- } \\
\text { bakht (2002), Gitman (2010) }\end{array}$ \\
$\begin{array}{l}\text { Retorno sobre o ativo total } \\
\text { (ROA) }\end{array}$ & $\frac{\text { EBIT }}{\text { Ativo Total }}$ & Blatt (2001) e Gitman (2010) \\
$\begin{array}{l}\text { Margem de lucro bruto (MLB) } \\
\text { Margem de lucro operacional } \\
\text { (MLO) }\end{array}$ & $\frac{\text { Vendas }- \text { CMV) }}{\text { Vendas }}$ & Groppelli e Nikbakht (2002) e \\
$\begin{array}{l}\text { Margem de lucro líquido } \\
\text { (MLL) }\end{array}$ & $\frac{\text { Gucro Líquido }}{\text { Vendas }}$ & $\begin{array}{l}\text { Groppelli e Nikbakht (2002) e } \\
\text { Gitman (2010) }\end{array}$ \\
\hline
\end{tabular}

Indicadores de desempenho financeiro

Liquidez corrente (LC)

Liquidez seca (LS)

$\frac{\text { Ativo Circulante }}{\text { Passivo Circulante }}$

Ativo Circulante - Estoques

Passivo Circulante
Groppelli e Nikbakht (2002),

Gitman (2010) e Blatt (2001) 


\begin{tabular}{|c|c|c|}
\hline Variável & Fórmula & Autores \\
\hline \multirow{2}{*}{ Liquidez imediata (LI) } & Disponível & \multirow{2}{*}{ Luz (2013) e Blatt (2001) } \\
\hline & $\overline{\text { Passivo Circulante }}$ & \\
\hline \multirow{2}{*}{ Liquidez geral (LG) } & Ativo Total & \multirow{2}{*}{ Blatt (2001) } \\
\hline & $\overline{(\text { Passivo Circulante }+ \text { Passivo Não Circulante) }}$ & \\
\hline \multicolumn{3}{|c|}{ Indicadores de desempenho de mercado } \\
\hline $\mathrm{Q}$ de Tobin (QT) & $\frac{(\text { Vlr ação ord. }+ \text { Vlr ação pref. })+(\text { Ativo cir. }- \text { dividas })}{\text { Ativo Total }}$ & Silveira (2002) \\
\hline \multirow{2}{*}{ Lucro por ação (LPA) } & Lucro Líquido & \multirow{2}{*}{ Rappaport (1998) } \\
\hline & $\overline{\text { Quantidade de Ações }}$ & \\
\hline \multirow{2}{*}{ Retorno da ação (RA) } & Preço da ação it - Preço da Ação it - 1 & \multirow{2}{*}{ Rappaport (1998) } \\
\hline & Preço da Ação it - 1 & \\
\hline
\end{tabular}

Com base nos índices de desempenho constantes na Tabela l, analisou-se inicialmente a estatística fatorial exploratória para verificar se os indicadores de desempenho se agruparam conforme a literatura, como: desempenho econômico, desempenho financeiro e desempenho de mercado. Em seguida, observou-se a análise fatorial para identificar os indicadores de desempenho com maior relevância para cada setor de atuação das empresas.

\section{DESCRIÇÃO E ANÁLISE DOS DADOS}

Apresentam-se nesta seção os resultados relativos à Análise Fatorial Exploratória realizada no presente estudo. Entretanto, é necessário destacar que em uma primeira análise foi constado que a variável $Q$ de Tobin ( $Q T$ ) teve que ser excluída por apresentar, na matriz de correlação anti-imagem que revela a adequação individual das variáveis à amostra, um nível de Mesure of Sampling Adequacy (MSA) menor do que 0,50, apesar de o teste de esfericidade indicar a possibilidade da Análise Fatorial. Assim, procedeu-se à Análise Fatorial com a exclusão da variável QT. A Tabela 2 apresenta os resultados do teste de KMO e a esfericidade de Bartlett:

Tabela 2

Teste de KMO e Bartlett

\begin{tabular}{ll}
\hline Medida Kaiser-Meyer-Olkin de adequação de amostragem & 0,656 \\
\hline Teste de esfericidade de Bartlett & \\
\hline Qui-quadrado aprox. & 3225,430 \\
\hline Df & 55 \\
\hline Sig. & 0,000 \\
\hline
\end{tabular}


Obteve-se pelo teste de esfericidade de Bartlett um valor $p$ de 0,000, ou seja, menor que o nível de significância de 0,05, rejeitando-se, portanto, a hipótese de que não há correlação entre as variáveis suficientes para a utilização da Análise Fatorial. Adicionalmente, o teste KMO, que mede a adequação da utilização da Análise Fatorial para a base de dados, apresentou um valor de, aproximadamente, 0,656, e de acordo com Pestana e Gageiro (2003), o KMO de 0,60 demonstra que há uma correlação razoável entre as variáveis. Nesse caso, os resultados apresentados (KMO e teste de esfericidade de Bartlett) indicam que há um nível de correlação entre as variáveis do presente estudo suficiente para a utilização da Análise Fatorial.

A seguir, na Tabela 3 apresenta-se a variância total explicada das variáveis da pesquisa:

Tabela 3

Variância total explicada

\begin{tabular}{llll}
\hline \multirow{2}{*}{ Componente } & \multicolumn{3}{c}{ Valores próprios iniciais } \\
\cline { 2 - 4 } & \multicolumn{2}{c}{ \% de variância } & \% cumulativa \\
\hline 1 & 3,399 & 30,899 & 30,899 \\
3 & 2,281 & 20,739 & 51,639 \\
4 & 1,125 & 10,226 & 61,865 \\
5 & 1,030 & 9,359 & 71,224 \\
6 & 0,891 & 8,099 & 79,323 \\
7 & 0,740 & 6,726 & 86,049 \\
8 & 0,617 & 5,609 & 91,658 \\
9 & 0,386 & 3,510 & 95,168 \\
10 & 0,244 & 2,221 & 97,389 \\
11 & 0,228 & 2,073 & 99,462 \\
\hline
\end{tabular}

De acordo com a Tabela 3 é possível verificar que, considerando o critério do autovalor superior a l, a extração de três fatores explica 61,8\% das variações totais dos 11 indicadores de desempenho. Entretanto, a Análise Fatorial, ainda considerando o critério do autovalor superior a l, aponta para um quarto fator que explica 9,3\% das variações totais. Verificou-se, também, que a matriz de correlação anti-imagem apresenta para as variáveis do estudo um nível MSA maior do que 0,50, considerado satisfatório e indicando que todas as variáveis devem permanecer na análise.

A seguir, na Tabela 4, apresenta-se o agrupamento dos três fatores, considerando o desempenho financeiro, econômico e de mercado: 
Tabela 4

Matriz de componente rotativa

\begin{tabular}{lllll}
\hline & Variáveis & \multicolumn{4}{c}{ Componente } \\
\cline { 2 - 4 } & & 1 & 2 & 3 \\
\hline LC & 0,953 & - & - & - \\
LS & 0,949 & - & - \\
LG & 0,752 & - & - \\
LI & 0,514 & - & - \\
MLO & - & 0,764 & - \\
MLL & - & 0,684 & - \\
MLB & - & 0,678 & - \\
ROE & - & 0,509 & 0,723 \\
ROA & - & - & 0,624 \\
RA & - & - & 0,591 \\
LPA & - & - & \\
\hline
\end{tabular}

Conforme apresentado na Tabela 4, o primeiro fator, responsável por 30,8\% das variações, refere-se a variáveis de liquidez relacionadas ao desempenho financeiro. Os indicadores de liquidez medem a solvência no curto prazo e são associados ao capital de giro. O resultado da Análise Fatorial confirma o que Blatt (2001), Groppelli e Nikbakht (2002), Gitman (2010) e Luz (2013) afirmam, que os indicadores considerados tradicionais utilizados para medir o desempenho financeiro das empresas são liquidez corrente (LC), liquidez seca (LS), liquidez imediata (LI) e liquidez geral (LG). Desse modo, a H2 (Os indicadores de desempenho liquidez corrente, liquidez seca, liquidez imediata e liquidez geral correspondem ao agrupamento de desempenho financeiro das empresas brasileiras analisadas) não foi rejeitada.

O segundo fator, que corresponde a $20,7 \%$ da variância explicada, agrupou as variáveis margem de lucro operacional (MLO), margem de lucro líquido ( $M L L)$, margem de lucro bruto $(M L B)$ e rentabilidade do patrimônio líquido ( $R O E)$, todas relativas ao desempenho econômico. Esse resultado corrobora o exposto por Blatt (2001), Groppelli e Nikbakht (2002) e Gitman (2010), que afirmam que os indicadores considerados para medir o desempenho econômico das empresas são ROE, margem de lucro bruto, margem de lucro operacional e margem de lucro líquido. Entretanto, observa-se que a variável rentabilidade do ativo (ROA) não se agrupou no fator, dessa maneira, rejeita-se a $\mathrm{Hl}$ (Os indicadores de desempenho ROA, ROE, margem de lucro bruto, margem de lucro operacional e margem de lucro líquido correspondem ao agrupamento de desempenho econômico das empresas brasileiras analisadas).

O terceiro fator, que corresponde a $10 \%$ da variância explicada, representa os indicadores relacionados ao desempenho de mercado. $O$ ROA se agrupou no fator de desempenho de mercado, porém tradicionalmente é considerado uma variável de 
desempenho econômico, conforme afirmam Blatt (2001) e Gitman (2010). Desse modo, a H3 (Os indicadores de desempenho $\mathrm{Q}$ de Tobin (QT), lucro por ação e retorno da ação correspondem ao agrupamento de desempenho de mercado das empresas brasileiras analisadas) foi rejeitada. Confirma-se nessa análise dos indicadores de mercado apenas o exposto por Rappaport (1998), que infere que o agrupamento para os indicadores de mercado e que representa a criação de valor das empresas corresponde ao lucro por ação (LPA) e ao retorno da ação (RA).

Apesar de a variável ROA ter sido agrupada com os indicadores de mercado e de o $\mathrm{Q}$ de Tobin (QT) ter sido inicialmente excluído da análise, considera-se, de modo geral, que apenas o grupo de desempenho financeiro está representado pelas suas respectivas variáveis, confirmando sua hipótese. Com base nessa análise, teve-se a consecução do objetivo geral da pesquisa.

Ainda, teve-se como objetivo específico analisar os determinantes de desempenho das empresas de acordo com cada setor, visto que na visão de Macedo e Corrar (2010), a utilização dos indicadores de desempenho varia de acordo com o setor de atuação da empresa. Dessa forma, apresentam-se na Tabela 5 os determinantes de desempenho de cada setor, observados pelas comunalidades dos indicadores:

Tabela 5

Comunalidades dos indicadores por setor de atuação

\begin{tabular}{|c|c|c|c|c|c|c|c|c|c|c|}
\hline Indicadores & $\begin{array}{l}\text { Bens } \\
\text { Ind. }\end{array}$ & $\begin{array}{l}\text { Cons. } \\
\text { Tran. }\end{array}$ & $\begin{array}{l}\text { Con. } \\
\text { Cícl. }\end{array}$ & $\begin{array}{c}\text { Con. N. } \\
\text { Cícl. }\end{array}$ & $\begin{array}{l}\text { Finan. } \\
\text { Outr. }\end{array}$ & $\begin{array}{l}\text { Mat. } \\
\text { Básic. }\end{array}$ & Petr. & $\begin{array}{l}\text { Tec. } \\
\text { Info. }\end{array}$ & Telec. & $\begin{array}{l}\text { Util. } \\
\text { Públ. }\end{array}$ \\
\hline ROE & $0,979^{*}$ & 0,625 & 0,752 & 0,440 & 0,878 & 0,659 & 0,990 & 0,975 & 0,866 & 0,795 \\
\hline ROA & $0,932^{*}$ & 0,608 & $0,922^{*}$ & $0,903^{*}$ & 0,876 & $0,954^{*}$ & 0,993 & 0,982 & 0,883 & 0,896 \\
\hline MLB & 0,672 & 0,459 & 0,621 & 0,739 & 0,653 & 0,788 & 0,997 & 0,942 & 0,599 & 0,467 \\
\hline MLO & 0,762 & 0,626 & 0,853 & $0,903^{*}$ & 0,065 & 0,838 & 0,993 & 0,991 & 0,828 & $0,908^{*}$ \\
\hline MLL & $0,973^{*}$ & 0,873 & $0,930^{*}$ & $0,929^{*}$ & 0,790 & 0,892 & 0,990 & 0,984 & $0,976^{*}$ & $0,946^{*}$ \\
\hline LC & $0,918^{*}$ & $0,933^{*}$ & $0,964^{*}$ & $0,943^{*}$ & $0,929^{*}$ & 0,840 & 0,999 & 0,920 & $0,954^{*}$ & $0,944^{*}$ \\
\hline LS & $0,927^{*}$ & $0,906^{*}$ & $0,933^{*}$ & $0,952^{*}$ & $0,924^{*}$ & $0,927^{*}$ & 0,994 & 0,992 & $0,946^{*}$ & $0,953^{*}$ \\
\hline LI & 0,716 & 0,727 & 0,433 & 0,870 & 0,559 & 0,738 & 0,996 & 0,989 & $0,908^{*}$ & 0,460 \\
\hline LG & 0,554 & 0,772 & $0,917^{*}$ & 0,660 & 0,625 & 0,590 & 0,999 & 0,904 & 0,472 & 0,638 \\
\hline LPA & $0,948^{*}$ & 0,226 & 0,771 & 0,604 & 0,724 & $0,912^{*}$ & 0,988 & 0,861 & $0,925^{*}$ & 0,645 \\
\hline RA & 0,788 & 0,377 & 0,507 & 0,485 & 0,591 & 0,515 & 0,817 & 0,765 & 0,792 & 0,470 \\
\hline KMO & 0,783 & 0,513 & 0,743 & 0,698 & 0,565 & 0,680 & - & 0,618 & 0,581 & 0,608 \\
\hline Sig. & 0,000 & 0,000 & 0,000 & 0,000 & 0,000 & 0,000 & - & 0,000 & 0,000 & 0,000 \\
\hline
\end{tabular}

Nota. Comunalidades entre 0,9 e l, que representam os indicadores com maior relevância.

Os valores das comunalidades, quanto mais próximo de 1 estiverem, representam maior poder de explicação dos fatores, o que pode sugerir maior relevância de determinado indicador para cada setor analisado. Dessa forma, com base nas comunalidades de cada 
setor com valores entre 0,9 e l, verificam-se os indicadores de desempenho com maior relevância para eles.

Para o setor de bens industriais (Bens Ind.) se observa que os indicadores de desempenho com maior relevância foram rentabilidade do patrimônio líquido (ROE), rentabilidade do ativo (ROA), margem de lucro líquido (MLL), liquidez corrente (LC), liquidez seca (LS) e lucro por ação (LPA), o que demonstra que indicadores de todos os três tipos de desempenho (financeiro, econômico e de mercado) são importantes para as empresas desse segmento.

Para o segmento de construção e transporte (Cons. Tran.) se observam como indicadores com maiores comunalidades, ou seja, relevância, os de desempenho financeiro, representados pelos indicadores de liquidez corrente (LC) e liquidez seca (LS). No setor de consumo cíclico (Con. Cícl.) destacam-se os indicadores de desempenho econômico rentabilidade do ativo ( $R O A$ ) e margem de lucro líquido ( $M L L)$ e também os indicadores de desempenho financeiro representados por liquidez corrente (LC), liquidez seca (LS) e liquidez geral (LG).

Com relação ao setor de consumo não cíclico (Con. N. Cícl.) os indicadores que se destacaram foram rentabilidade do ativo (ROA), margem de lucro operacional (MLO) e margem de lucro líquido (MLL), os quais são indicadores de desempenho econômico, e também os indicadores de desempenho financeiro, como liquidez corrente (LC) e liquidez seca (LS).

Os indicadores do setor financeiro e outros (Finan. Outr.) que se destacaram foram os de desempenho financeiro, representados por liquidez corrente (LC) e liquidez seca (LS). Para o setor de materiais básicos (Mat. Básic.) os indicadores que se destacaram foram rentabilidade do ativo (ROA), o qual é desempenho econômico; liquidez seca (LS), que é desempenho financeiro; e lucro por ação (LPA), o qual é do grupo de desempenho de mercado. No setor petróleo (Petr.) os indicadores que se destacaram foram todos os analisados, menos o de retorno da ação (RA), entretanto, esse fato pode ter sido em decorrência da baixa amostra analisada para esse setor, visto que poucas empresas listadas na bolsa compõem esse setor de atuação. Da mesma forma, em razão da baixa amostra analisada do setor de tecnologia da informação (Tec. Info.) (por constarem poucas empresas listadas na bolsa nesse segmento), observou-se que somente os indicadores de desempenho de mercado lucro por ação (LPA) e retorno da ação (RA) não se demonstraram relevantes.

Quanto ao setor de telecomunicações (Telec.), os indicadores que se destacaram foram margem de lucro líquido ( $M L L)$, que é desempenho econômico, liquidez corrente (LC), liquidez seca (LS) e liquidez imediata (LI), os quais são indicadores de desempenho financeiro; e lucro por ação, que representa desempenho de mercado. Já com relação ao setor de atuação de utilidade pública (Util. Públ.), os indicadores que se destacaram foram margem de lucro operacional (MLO) e margem de lucro líquido (MLL), os quais 
são indicadores de desempenho econômico; ainda se destacaram os indicadores financeiros, como liquidez corrente (LC) e liquidez seca (LS).

De maneira geral, com base nos resultados da Tabela 5, pode-se observar que para os setores bens industriais, materiais básicos e de telecomunicações, indicadores do grupo de desempenho econômico, financeiro e de mercado se demonstraram com maior relevância, - que infere que empresas desses setores devem concentrar atenção aos indicadores que demonstram sua rentabilidade, liquidez e criação de valor. Assim, as empresas desses setores estão primando pela rentabilidade, o que, de acordo com Pimentel et al. (2005), demonstra - êxito econômico pela magnitude do lucro líquido contábil. Também, ao considerarem indicadores financeiros, as empresas estão se preocupando com indicadores de liquidez, os quais, segundo Gitman (2010) e Luz (2013) revelam a solvência destas, bem como as dificuldades financeiras. E ainda, ao primarem por indicadores de mercado, os quais revelam a valorização das empresas no mercado, conforme Frezatti (1998), demonstram o quanto de valor foi gerado no mercado pelo investimento feito pelos acionistas.

Para o setor construção/transporte e financeiro/outros se destacaram somente os indicadores financeiros, o que pode ser inferido que empresas desses setores devem dar maior atenção aos indicadores de liquidez, os quais revelam a solvência da empresa (Gitman, 2010; Luz, 2013). Os setores consumo cíclico, consumo não cíclico e de utilidade pública tiveram os indicadores de desempenho econômico e financeiro com maior relevância, o que pode sugerir que esses setores devem dar maior ênfase à rentabilidade (Pimentel et al., 2005) e à liquidez de seus negócios (Gitman, 2010; Luz, 2013). Por fim, para os setores de petróleo e de tecnologia da informação, por terem poucas empresas em seus segmentos, os resultados demonstraram-se um tanto inconclusivos, visto que quase todos os indicadores analisados se demonstraram com relevância entre 0,9 e 1. Para o setor de petróleo todos os indicadores se demonstraram relevantes, e para o setor de tecnologia da informação os indicadores de desempenho econômico e financeiro se demonstraram com maior relevância. Assim, observase que de acordo com as características de cada setor, estes apresentam determinados indicadores mais relevantes do que outros agrupamentos de desempenho.

\section{CONSIDERAÇÕES FINAIS}

O objetivo geral do presente estudo foi o de verificar o agrupamento de indicadores de desempenho em três dimensões, como: desempenho econômico, desempenho financeiro e desempenho de mercado, por meio de análise fatorial. Ainda, como objetivo específico, teve-se por intuito analisar os determinantes de desempenho das empresas de acordo com cada setor. Para isso, adotou-se como procedimentos metodológicos aspectos descritivos, 
documental e quantitativo. A amostra do estudo correspondeu a 101 empresas no período de 2010 a 2015. Para a análise dos dados, utilizou-se análise fatorial.

O resultado referente ao objetivo geral demonstrou que a análise fatorial gerou três fatores de agrupamentos de indicadores de desempenho. $O$ primeiro fator refere-se ao desempenho financeiro, o qual agrupou os indicadores de liquidez corrente, liquidez seca, liquidez imediata e liquidez geral, conforme Groppelli e Nikbakht (2002), Gitman (2010), Blatt (2001) e Luz (2013). Desta forma, não se rejeitou a hipótese H2 (Os indicadores de desempenho liquidez corrente, liquidez seca, liquidez imediata e liquidez geral correspondem ao agrupamento de desempenho financeiro das empresas brasileiras analisadas).

Quanto ao agrupamento do desempenho econômico, observou-se que os indicadores de lucro operacional, margem de lucro líquido, margem de lucro bruto e rentabilidade do patrimônio líquido se agruparam neste fator, sendo que todas estes correspondiam a indicadores conforme indicada por Groppelli e Nikbakht (2002), Gitman (2010) e Blatt (2001). Porém, o indicador rentabilidade do ativo não se agrupou ao desempenho econômico, mas ao desempenho de mercado, além das variáveis de desempenho de mercado lucro por ação e retorno da ação. Dessa forma, rejeitaram-se as hipóteses $\mathrm{Hl}$ (Os indicadores de desempenho ROA, ROE, margem de lucro bruto, margem de lucro operacional e margem de lucro líquido correspondem ao agrupamento de desempenho econômico das empresas brasileiras analisadas) e H3 (Os indicadores de desempenho $\mathrm{Q}$ de Tobin (QT), lucro por ação e retorno da ação correspondem ao agrupamento de desempenho de mercado das empresas brasileiras analisadas). Assim, de acordo com o analisado, para as empresas brasileiras apenas os indicadores de desempenho financeiro se confirmaram, por seu agrupamento em um único fator.

Ainda, observaram-se com base na análise do objetivo específico que indicadores que representam rentabilidade, liquidez e valor da empresa no mercado são os que se destacaram como mais relevantes para as empresas do setor de bens industriais, materiais básicos e de telecomunicações. Já para as empresas de construção/transporte e financeiro/outros se destacaram de forma mais relevante os indicadores de liquidez. Para as empresas dos setores consumo cíclico, consumo não cíclico e de utilidade pública, verificou-se maior ênfase em indicadores de rentabilidade e liquidez. Esses resultados indicaram que de acordo com os setores de atuação há variação da relevância dos indicadores de desempenho, o que sugere para as empresas que a avaliação de desempenho pode ser realizada de forma concentrada em determinados indicadores, de acordo com cada setor de atuação, demonstrando as informações que são as mais relevantes para elas. Consequentemente, utilizar um único índice para avaliar de maneira conjunta as empresas de todos os setores pode não ser adequado, conforme apontou análise estatística multivariada no presente estudo.

Com base nos resultados apresentados no presente estudo, sugere-se para pesquisas futuras o aprofundamento da análise, a fim de se observarem particularidades que possam estar influenciando a sua associação com o lucro por ação e o retorno da ação, ou ainda, se o lucro por 
ação e o retorno da ação poderiam estar associados com os indicadores econômicos, dos quais o ROA faz parte. Os futuros estudos também poderiam explorar em maior profundidade a razão pela qual a avaliação de desempenho de diferentes indicadores apresentou maior relevância entre os variados setores de atuação. Além disso, considerando que o estudo utilizou dados de setores no contexto brasileiro, sugere-se realizar a avaliação também em outros países para verificar se os resultados encontrados podem ser semelhantes ou não.

\section{REFERÊECIAS}

Bacidore, J. M., Boquist, J. A., Milbourn, T. T., \& Thakor, A. V. (1997). The search for the best financial performance measure. Financial Analysts Journal, 53(3), 11-20.

Blatt, A. (2001). Análise de Balanços: Estrutura e avaliação das demonstrações financeiras e contábeis. São Paulo: Makros Books.

Bortoluzzi, S. C., Ensslin, R. S., Lyrio, M. V. L., \& Ensslin, L. (2011). Avaliação de desempenho econômico-financeiro: Uma proposta de integração de indicadores contábeis tradicionais por meio da metodologia multicritério de apoio à decisão construtivista (MCDA-C). Revista Alcance, 18(2).

Braga, R., Nossa, V., \& Marques, J. A. V. D. C. (2004). Uma proposta para a análise integrada da liquidez e rentabilidade das empresas. Revista Contabilidade \& Finanças, 15(SPE), 51-64.

Brito, E. P. Z., Brito, L. A. L., \& Morganti, F. (2009). Inovação e o desempenho empresarial: Lucro ou crescimento? RAE Eletrônica, $8(1)$.

Dumontier, P., \& Raffournier, B. (2002). Accounting and Capital Markets: A Survey of the European Evidence. The European Accounting Review, 11(1), 119-151.

Firer, S., \& Williams, S. M. (2003). Intellectual capital and traditional measures of corporate performance. Journal of intellectual capital, 4(3), 348-360.

Fischmann, A. A., \& Zilber, M. A. (2009). Utilização de indicadores de desempenho para a tomada de decisões estratégicas: Um sistema de controle. Revista de Administração Mackenzie (Mackenzie Management Review), 1(1).

Frezatti, F. (1998). Valor da empresa: Avaliação de ativos pela abordagem do resultado econômico residual. Caderno de Estudos, 19, 1-16. 
Gitman, L. J. (2010). Princípios de administração financeira. São Paulo: Pearson Prentice Hall.

Groppelli, A. A. \& Nikbakht, E. (2002). Administração financeira. São Paulo: Saraiva.

Healy, P. M., \& Palepu, K. G. (2007). Business analysis and valuation: Using financial statements, text and cases. Cengage Learning.

Hendriksen, E. S., \& Van Breda, M. F. (1999). Teoria da contabilidade. Tradução Antonio Zoratto Sanvicente. São Paulo: Atlas.

Luz, E. R. (2013). Indicadores tradicionais de liquidez e de rentabilidade: Um estudo comparativo da média setorial das empresas brasileiras nos anos 2000 a 2010. Revista AD. Mpg Gestão Estratégica, 6(2), 87-95.

Macedo, M. A. S., \& Corrar, L. J. (2010). Análise do desempenho contábil-financeiro de seguradoras no Brasil no ano de 2007: Um estudo apoiado em análise hierárquica (AHP). Contabilidade Vista \& Revista, 21(3), 135-165.

Martins, G. A., \& Theóphilo, C. R. (2007). Metodologia da investigação científica para ciências sociais aplicadas. São Paulo: Atlas.

Matarazzo, D. C. (2010). Análise financeira de balanços: Abordagem gerencial. (7 ${ }^{a}$ ed.). São Paulo: Atlas.

Oliveira, S. L. (2002). Tratado de metodologia científica: Projetos de pesquisas, TGI,TCC, monografias, dissertações e teses. ( $2^{a}$ ed.). São Paulo: Pioneira.

Pestana, M. H., \& Gageiro, J. N. (2003). Análise de dados para ciências sociais: A complementaridade do SPSS. Lisboa, Portugal: Edições Sílabo.

Pimentel, R. C., Braga, R., \& Nova, S. P. C. C. (2005). Interação entre rentabilidade e liquidez: Um estudo exploratório. Revista de Contabilidade do Mestrado em Ciências Contábeis da UERJ, 10(2).

Pimentel, R. C. (2008). Dilema entre Liquidez e Rentabilidade: Um Estudo Empírico em Empresas Brasileiras. Anais do Encontro da ANPAD, Rio de Janeiro, 32.

Rappaport, A. (1998). Creating shareholder value. New York: Free Press. 
Richardson, R. J., \& Peres, J. A. S. (1989). Pesquisa social: Métodos e técnicas. ( ${ }^{a}$ ed.). São Paulo: Atlas.

Santos, J. O. (2006). A contribuição da determinação do valor da empresa e do $E \mathrm{~A}^{\oplus}$ no processo de análise de crédito. REGE Revista de Gestão, 13(3), 41-55.

Silveira, A. D. M. (2002). Governança corporativa, desempenho e valor da empresa no Brasil (Tese de doutorado). Universidade de São Paulo, São Paulo.

Smyth, D. J., Samuels, J. M., \& Tzoannos, J. (1972). Patents, profitability, liquidity and firm size. Applied Economics, 4(2), 77-86.

Souza, J. A. S., Neto, \& Martins, H. C. (2010). Finanças e governança corporativa: Práticas e estudo de caso. Elsevier Brasil.

Teixeira, N. M. D., \& Amaro, A. G. C. (2013). Avaliação do desempenho financeiro e da criação de valor-um estudo de caso. Revista Universo Contábil, 9(4), 157-178.

Van Horne, J. C. (1995). Financial Management and Policy. Englewood Cliffs: Printice-Hall.

Venkatraman, N., \& Ramanujam, V. (1986). Measurement of business performance in strategy research: A comparison of approaches. Academy of management review, 11(4), 801-814.

Wernke, R., \& Lembeck, M. (2004). Análise de rentabilidade dos segmentos de mercado de empresa distribuidora de mercadorias. Revista Contabilidade \& Finanças, 15(35), 68-83.

Young, S. D., \& O'Byrn, S. F. (2003). EVA e gestão baseada em valor. Porto Alegre: Bookman.

Como citar este artigo:

\section{ABNT}

SILVA, Alini da et al. Análise exploratória de indicadores de desempenho. RACE, Revista de Administração, Contabilidade e Economia, Joaçaba: Ed. Unoesc, v. 18, n. 1, p. 157-176, jan./abr. 2019. Disponível em: https://portalperiodicos.unoesc.edu.br/race. Acesso em: dia/ mês/ano.

\section{APA}

Silva, A. da, Ramos, S. P., Kroenke, A., \& Hein, N. (2019). Análise exploratória de indicadores de desempenho. RACE, Revista de Administração, Contabilidade e Economia, 18(1), 157 176. Recuperado de http://editora.unoesc.edu.br/index.php/race 
